\title{
The theory and research review of Shared leadership
}

\author{
Danyang Wang, Lu Ma \\ School of Guangxi University of Science and Technology, Liuzhou, Guangxi, China; \\ 964216798@qq.com
}

\begin{abstract}
Keywords: Shared leadership, human resources management, organizational performance
\end{abstract}
\begin{abstract}
Shared leadership behavior as a leader form in the team or organization, through multiple members of the team, which affect the performance in the team and organization. This paper introduces the concept of Shared leadership in turn, the connotation, structure type and measuring method, and the shared leadership and sorted out the relationship between the other variables, finally summarizes the shortcomings of existing research and enlightenment to the domestic research.
\end{abstract}

\section{The Concept of Shared Leadership}

Shared leadership as a way to more and more used for the organization leadership, the concept has not yet formed a unified conclusion, so it is very important to study its evolution and the nature of. As early as 1987, scholar Hackman and puts forward the execution of the work and need to rely on the team members to achieve the goal of each other to solve the problem, then more and more researchers have found that by the level of the team members to provide leadership is more suitable for the development of The Times [1]. Pearce and Conger (2002) proposed by scholars, Shared leadership is through the integration of professional knowledge, knowledge sharing, and team member's decisions and take responsibility together, a kind of leadership style to the realization of ultimate team goal [2]. Scholars such as Bligh and Pearce (2006) argue that this leadership style belongs to a collective leadership, involving multiple individuals rather than just formal leadership. In addition, Chinese scholars Liu Bo escape (2009) based on the background of China, the Shared leadership is defined as "a group of dynamic, interactive influence process, according to the task in the process characteristics of led by the team members with expertise in the corresponding transformation function and according to the situation changes the dynamic change of leading role to achieve the goal of team and organization".

Currently, although many scholars on the concept of Shared leadership has put forward different views, but these concepts have a common theme, that is the style of leadership on behalf of the team or organization process. The research, represented by Carson scholar (2007), is a good example of this, and he defines Shared leadership as an emerging team attribute. This is because its leadership affects the influence of multiple team members, which can significantly influence the performance of teams and organizations. Ensley and Pearce (2003) the definition of scholars such as well reflect the characteristics of the Shared leadership as a team process, is to the whole team as a whole, rather than individual process, led by a designated individual reflects Shared leadership for all members of the group, rather than a single member. Kozlowski and Bell (2002), and other scholars have pointed out, based on team work structure type Shared leadership and its application have been more and more attention and research, to a great extent, is due to the widespread adoption of structured work team organization. The leadership of the team is compared with traditional management and personal work arrangements, and presents new challenges in management. This especially in the project team is made up of skilled employees and fully shown knowledge staff team, their task is complex and has the certain difficulty, and asked them to highly coordination and the ability to integrate and share their knowledge and expertise. Therefore, Shared leadership is through the integration of professional knowledge, knowledge sharing, and team member's decisions and take responsibility together, a kind of leadership style to the realization of ultimate team goal. 
In addition, scholars have conducted in-depth research on the main characteristics of Shared leadership. Sharing of team leadership is a kind of way by the collective leadership of the leadership team members, is characterized by collaborative decision making and to share the results, and describe Shared leadership as a team member in order to achieve the goal and mutual influence between, the process of leadership. Carson and Tesluk (2007) proposed by scholars, Shared leadership is usually composed of related knowledge and the ability of the team, the team members have the ability to participate in collaborative decision-making, can affect and support other team members, enhance the vitality of the team, responsible for the results, the behavior is considered to be the main characteristic of Shared leadership.

\section{The Structure and Measurement of Shared Leadership}

\subsection{The Structure of Shared Leadership.}

For a long time, scholars at home and abroad have carried out the research on the Shared leadership, and proposed the structural models of different dimensions. Mayo (2003) to build the two-dimensional structure of Shared leadership model, namely the density of Shared leadership and team decentralization, this model is based on the theory of social network analysis based on the building. By understanding the degree of leadership network density and team decentralization, the level of team sharing leadership is determined. Sharing leadership density refers to the number or degree of leadership that can be felt in a team. The decentralization of the team refers to the concentration of the power of the team leader, which is centralization if the leader ACTS in a dense, decentralized way.

Yukl (1999) offers a three-dimensional model of Shared leadership, namely transformational, relation-oriented, and working oriented. Transformation-oriented means that teams can adapt to the work environment more flexibly by encouraging employees to innovate and learn from each other. Relationship orientation refers to building a good working environment for the team by strengthening the cooperation between teams, improving the relationships among the team members and creating a good working environment for the team. Work oriented refers to the employee's ability to set goals and other ways to improve the efficiency of the work and to achieve the performance in time.

Liu boyi (2009) builds a four-factor model of Shared leadership based on the Chinese scenario, namely performance expectations, team learning, collaboration and responsibility sharing. Performance expectations refer to the performance of the performance through rigorous requirements for the efficiency and quality of your work; Team learning refers to the purpose of improving team intelligence, expertise, and learning new knowledge and skills through collective discussions. Collaboration means working with others to work together and trust each other to achieve the team's goals. Power and responsibility sharing refers to all team members Shared leadership, Shared responsibility, according to the working environment and members expertise by different team members the role as team leader.

Sims (1996) offers a four-dimensional model of Shared leadership, guided by leadership, transactional leadership, transformational leadership, and authorization leadership. After Pearce and Sims (2002), on this basis, the Shared leadership five-dimensional structure model is put forward, namely, transformational leadership, guidance leadership, transactional leadership, punishment and authorization type leadership. Among them, transformational leaders include challenges, motivation, vision, intellectual stimulation, flexible communication, performance expectations and personalized care. Guided leaders include the ability to assign targets and issue orders, depending on the role of the office; Transactional leadership involves the provision of material or spiritual rewards to subordinates; Punishment leadership refers to the behavior of a leader who relies on coercive force to coerce and punish subordinates. Authorization leadership refers to the act of assigning a target to a subordinate and encouraging the self-directed behavior of the subordinate to the [3]. 


\subsection{The Measurement of Shared Leadership.}

There are two main approaches to the current measurement of Shared leadership, respectively, questionnaire survey and social network analysis. The questionnaire survey means that the questionnaire is prepared according to the existing scale or the appropriate scale. The Shared leadership scale consists of a four-dimensional scale developed by Wood (2005), with 18 entries making up the [4]. The four-dimensional scale developed by liu boyi (2009) has 20 entries to make up. Pearce \& Sims (2002) developed a five-dimension scale with 35 entries to make up. Among them, because our country Liu Bo scholar is based on Chinese situation and development of scale, therefore, Chinese scholars in the study of Shared leadership most used Liu Bo escape scholars developed four dimension scale.

Second, social network analysis is a research method to study the relationship between a group of actors. A set of actors can be people, communities, groups, organizations, countries, etc., and their relationship patterns reflect the phenomenon or data that is the focus of network analysis. Social network analysis as a quantitative analysis, through the measurement of Shared leadership and other variables, the relationship between the behaviors of the defects in the measurement can be made up.

\section{Shared Leadership Impact Mechanism Research}

\subsection{The Former Dependent Variable of the Shared Leadership.}

With a review of the literature found that there are many factors will positively influence Shared leadership, and its antecedent can be roughly classified into three categories: support factors, characteristics and composition of vertical leadership and team members. The support factors in the Shared leadership variables include team support, reward and information level. Vertical leadership, also known as hierarchical leadership, is seen as a leader's formal, external, or internal leadership. In contrast, Shared leadership is an informal, internal leadership by team members. Some scholars believe that part of the behavior of the vertical leadership can promote the development of Shared leadership, and team leaders can encourage Shared leadership to implement. In terms of characteristics and composition of the team members, independent sample t-test and single factor variance analysis can explore different individual and organizational characteristics variables, including gender, age, marriage, level of education, working years, job category, the nature of the enterprise, this paper discusses the characteristics and composition of the team members with the correlation between Shared leadership, research shows that different individuals and organizational characteristics variables in a Shared leadership and its various dimensions have different difference.

\subsection{The Former Dependent Variable of the Shared Leadership.}

Shared leadership ultimately affects team performance by influencing organizational processes including cognition, emotion and motivation. The existing Shared leadership behavior research literature at home and abroad, there have been many organizational behavior scholars in the related research results verified the Shared leadership behavior significantly positive effect on team performance. Carson (2007), the social network model analysis method, to 59 consulting team leadership behavior of the longitudinal analysis, the results prove that stimulates type Shared leadership behavior on team performance [5]. Studies of student samples, such as Avolio (1996), show that Shared leadership behaviors are significantly correlated with self-assessment performance. Shared leadership also has a significant positive effect on team satisfaction. The active participation of team members in the decision-making process affects the role identification, stress release, and satisfaction of the team members.

\subsection{The Former Dependent Variable of the Shared Leadership.}

Shared leadership is not only helpful for improving team performance, but also for employee behavior. Dorothy (2013) in a nationwide questionnaire through the network, discusses the Shared leadership influence on staff knowledge hidden behavior, the results showed that the Shared leadership in knowledge hidden behavior have a significant positive prediction function, and self-efficacy and trust in Shared leadership for knowledge hidden in the intermediary effect 
significantly, the influence of leadership team size in the sharing of knowledge hidden significantly the regulating effects. In addition, the Chinese scholars Wen Peng and Zhou Lihong (2016) through the analysis of the survey questions to 356 copies of the library staff, Shared leadership and librarians are discussed the relationship between the individual innovation actively, the result shows that Shared leadership by influencing the leader - member exchange and learning goals orientation, which affects the initiative of the librarians.

\section{Summary}

Throughout both at home and abroad in recent years, Shared leadership of the main related research results, some variables currently only has carried on the theoretical research, relevant empirical research is less, such as the sense of team support, information level, so in the future study of team support, information level variables such as the relationship between Shared leadership do related empirical studies; Shared leadership variables related research more focused on the result of the team and organizational level, the future can be aimed at individual level to study the relevant variables, type Shared leadership impact on employee behavior; Shared leadership more empirical research methods as questionnaire investigation, can try to use social network analysis in the future to Shared leadership and study the relationship between the other variables, in order to make up for the inadequacy of behavior that measurement. Related empirical study, will not only promote the theoretical research in this field, to expand its theoretical content, also is to further change our organization management beneficial enlightenment and help.

\section{References}

[1]. Wang D, Waldman D A, Zhang Z. A meta-analysis of shared leadership and team effectiveness. [J]. Journal of Applied Psychology, 2014, 99 (2) : 181-98.

[2]. Pearce C L, Conger J A. Reframing the Hows and Whys of Leadership[J]. 2002.

[3]. Day D V, Gronn P, Salas E. Leadership capacity in teams [J]. Leadership Quarterly, 2004, 15 (6) : 857-880.

[4]. Pontiff J, Woodgate A. Shares Outstanding and Cross-Sectional Returns[J]. Ssrn Electronic Journal, 2005.

[5]. Carson J B, Marrone J A. Shared Leadership in Teams: An Investigation of Antecedent Conditions and Performance[J]. Academy of Management Journal, 2007, 50 (5):1217-1234. 